A disadvantage of the method is connected with the activity of ATPase in tissue homogenates. If the activity of this enzyme is high compared with the ATP-forming enzyme, then the ATP cannot be coupled to the reduction of TPN. The extent to which the activity of the 'coupling enzyme' can be raised is limited, and so successful competition between the 'coupling enzyme' and the ATPase cannot always be arranged. If too much 'coupling enzyme' is added, then the reduction of TPN due to an unidentified substance in the preparation makes the optical density too high to be measured with the accuracy required for the determination of reaction velocities. For this reason it has been found advantageous to reduce the ATPase activity of some tissues, e.g. brain (see also Oliver, 1954), liver, kidney and spleen. If the tissues are homogenized in $0.1 \mathrm{M}-\mathrm{KCl}$ and centrifuged at $19000 \mathrm{~g}$ for 15 min., then much of the ATPase is removed.

The rates of reaction catalysed by $0.1-0.5 \mathrm{mg}$. wet weight of muscle are usually measured in routine work, while for other tissues ten times this amount, i.e. about $5 \mathrm{mg}$., can be satisfactorily assayed. The use of such a method for those interested in studies where only small amounts of tissue are available can be appreciated.

\section{SUMMARY}

1. A rapid spectrophotometric method has been developed for the assay of creatine phosphokinase and myokinase in tissue extracts and homogenates. The formation of ATP by these enzymes is coupled to the reduction of TPN and the rate of reduction gives a measure of the activities.

2. The sensitivity of the method enables the determination of enzymic activities in tissue preparations diluted as much as one part in 20000 corresponding to a quantity of tissue of about $300 \mu \mathrm{g}$. wet weight. Under these conditions reactions due to endogenous substances are negligible.

3. The method has been applied to the measurement of creatine phosphokinase and myokinase in various tissues of the rat.

The author wishes to thank Professor H. A. Krebs, F.R.S., for encouragement and advice, and $\mathrm{Mr} \mathrm{A}$. E. Nicholson for technical assistance.

\section{REFERENCES}

Askonas, B. A. (1951). Ph.D. Dissertation, Cambridge University.

Banga, I. (1943). Stud. Inst. med. Chem. Univ. Sreged, 3, 59.

Campbell, H. \& Simpson, J. A. (1953). Chem. \& Ind. p. 887. Chappell, J. B. \& Perry, S. V. (1954). Biochem. J. 57, 421. Eggleston, L. V. \& Hems, R. (1952). Biochem. J. 52, 156. Ennor, A. H. \& Rosenberg, H. (1954). Biochem. J. 57, 295. Ennor, A. H. \& Stocken, L. A. (1948). Biochem. J. 43, 190. Hanes, C. S. \& Isherwood, F. A. (1949). Nature, Lond., $164,1107$.

Horecker, B. L. \& Kornberg, A. (1948). J. biol. Chem. 175, 385.

Kalckar, H. M. (1943). J. biol. Chem. 148, 127.

Kalckar, H. M. (1947). J. biol. Chem. 167, 467.

Kornberg, A. (1950). J. biol. Chem. 182, 779.

Krebs, H. A. \& Hems, R. (1953). Biochim. biophys. Acta, $12,172$.

Kuby, S. A., Noda, L. \& Lardy, H. A. (1954). J. biol. Chem. $209,191$.

LePage, G. A. (1949). In Manometric Techniques and Tissue Metabolism. Minneapolis: Burgess Publishing Co. Narayanaswami, A. (1952). Biochem. J. 52, 295.

Oliver, I. T. (1954). Biochim. biophys. Acta, 14, 587.

Seigmiller, J. E. \& Horecker, B. L. (1951). J. biol. Chem. $192,175$.

Slater, E. C. (1953). Biochem. J. 53, 157.

Strehler, B. L. \& Totter, J. R. (1952). Arch. Biochem. Biophys. 40, 28.

\title{
Peroxidatic Activity of Catalase
}

\author{
By H. LASER* \\ Molteno Institute, University of Cambridge
}

(Received 17 February 1955)

The peroxidatic function of catalase consists in its ability to catalyse the oxidation by hydrogen peroxide of different substances, such as alcohols (Keilin \& Hartree, 1936, 1945b), nitrite (Heppel \& Porterfield, 1949), and formate (Chance, 1948). This property was first revealed in experiments (Keilin \& Hartree, 1936) in which the peroxide was

* Member of the Scientific Staff, Medical Research Council. produced as the result of a primary enzymic reaction, as for example the oxidation of hypoxanthine by xanthine oxidase. When this reaction was allowed to take place in the presence of catalase and ethanol, the latter underwent oxidation to aldehyde. Attempts to obtain peroxidatic oxidation of ethanol by preformed free $\mathrm{H}_{2} \mathrm{O}_{2}$ in presence of catalase were at first unsuccessful (Keilin \& Hartree, 1936). Later on, however, very small 
yields of peroxidatic oxidation were obtained, when $\mathrm{H}_{2} \mathrm{O}_{2}$ was added to ethanol and catalase by volatilization or in the form of a fine mist produced by an atomizer (Keilin \& Hartree, 1945b) or by diffusion from the open end of a fine capillary (Anan, 1951). There was, however, a marked difference in the degree of peroxidatic oxidation by enzymically produced peroxide and by a solution of free $\mathrm{H}_{2} \mathrm{O}_{2}$. Whereas in the coupled oxidation of ethanol almost all the $\mathrm{H}_{2} \mathrm{O}_{2}$ formed in the primary reaction is used for the secondary oxidation process, thereby oxidizing an equivalent amount of ethanol, in the oxidation of ethanol by a solution of $\mathrm{H}_{2} \mathrm{O}_{2}$ and catalase only a small fraction of $\mathrm{H}_{2} \mathrm{O}_{2}$, at best a few per cent, is utilized for this purpose, the main portion being decomposed catalatically.

The method used in these experiments involves the introduction of peroxide into a catalase-containing buffer solution by dialysis and allows the peroxide to be added in known amounts and at predetermined rates. The dialysed $\mathrm{H}_{2} \mathrm{O}_{2}$ is instantaneously decomposed catalatically, the $\mathrm{O}_{2}$ evolved being determined manometrically. However, in presence of ethanol the catalatic decomposition of diffused $\mathrm{H}_{2} \mathrm{O}_{2}$ is depressed in favour of peroxidatic oxidation of the added ethanol. A preliminary report of these experiments has previously been given (Laser, 1954a, $b$ ).

\section{METHODS}

The manometer vessel (Fig. 1). This consists of an upper part $A$ and a lower part $B$ which at their open circumference are drawn out into strong flanges $C$ accurately ground into plane surfaces. Between these flanges lies the cellophan membrane $D$. Part $B$ of the vessel is, at its lower end, provided with a tap $E$ (similar to that introduced by Dixon \& Keilin (1933) in their method for the determination of the respiratory quotient) which communicates with the outside through $e$. The key $F$ of this tap, which is secured in its barrel by a rubber ring (Fig. 2, $R$ ) resting in the groove $H$, is hollow and in the submerged vessel is filled with water which enters through the open ends of its handle $\left(f_{1}\right.$ and $\left.f_{2}\right)$, whereby temperature equilibration of the vessel contents is facilitated. The handle of the key is asymmetric, $f_{2}$ being longer than $f_{1}$; thus $f_{2}$ corresponds to the position of the cavity $G$ in the assembled vessel, an arrangement which facilitates orientation and manipulation of the key $F$ during the experimental period. The cavity $G$ receives the peroxide to be dialysed, which is released into the lower part of the vessel at $t=0$ by turning the handle so as to connect $G$ with $B$. A length of glass rod $J$ is included in the lower part of the vessel. Its dimensions are such that it will easily slide into the cavity $G$ at $t=0$, thus displacing the peroxide, releasing it into $B$ and thereby establishing a known initial $\mathrm{H}_{2} \mathrm{O}_{2}$ concentration in $B$ at $t=0$. The cavity $G$ holds about $0.5 \mathrm{ml}$. while the capacity of the lower part $B$ is about $8 \mathrm{ml}$. The upper part $A$ has been made in two sizes ( 8 and $15 \mathrm{ml}$.) which can alternatively be used on the same lower part according to the requirements of the experiment. The upper joint of the vessel $k$ is a standard size.
Manipulation. Apiezon M (Edwards and Co.) has been used for greasing the flanges and the key (Fig. $1, C$ and $F$ ) at a bath temperature of $38^{\circ}$. At lower temperatures a softer grease is required for the key $F$ only. Cellophan squares, approximately $80 \times 80 \mathrm{~mm}$., are soaked in water before assembling the vessels, in order to prevent subsequent shrivelling of the membrane on contact with liquid.

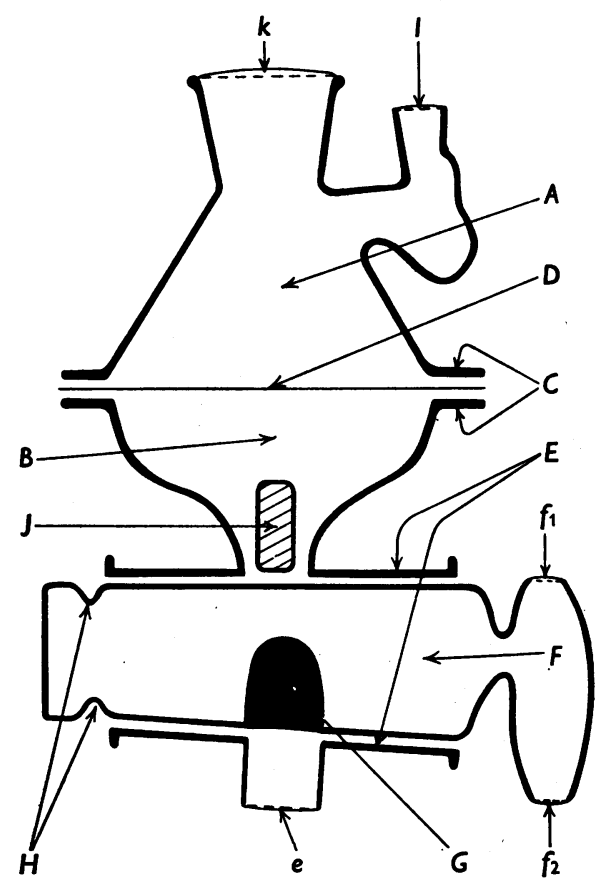

Fig. 1. Dialysis vessel. $A$, upper part; $B$, lower part; $C$, plane-parallel flanges; $D$, cellophan membrane; $E$, barrel of tap communicating through $e$ with the outside; $F$, key to barrel $E$; $G$, cavity for receiving substrate to be dialysed; $H$, groove for positioning rubber ring (see Fig. 2); $f_{1}$ and $f_{2}$ asymmetric handle of $F\left(f_{2}\right.$ corresponding to position of $G$ ); $J$, glass-rod; $k$, standard joint; $l$, side-bulb outlet.

A cellophan square is then dried between filter paper, and the lower part of the vessel, without the key $F$, is pressed on to the membrane-the grease on its flange having been warmed over a microburner-and, with the membrane adhering to it, at once transferred to a flat glass plate covered with smooth black paper. By applying a downward pressure combined with a slight lateral movement, the seal between the membrane and the flange is effected which, viewed against the black background, should be shiny and free from enclosed air bubbles. The protruding parts of the membrane are then turned over on to the vessel, whereby the membrane is retained in an evenly stretched position. Next, the greased and warmed flange of the upper part $A$ is pressed into position opposite the lower part, the correct seal being effected when both flanges appear transparent without streaks. The two parts are secured against each other by rubber bands or metal 
springs (Fig. 2, S) stretched between three sets of hooks. This ensures a firm fastening of the two parts against each other which has been proved to stand up to any manometric pressure likely to be developed.

The vessel is next inverted and put in a vertical position on to a greased standard manometer joint (suitably held in a clamp), which has a sealed-off capillary. The lower part $B$ is now uppermost. Next, the side bulb is closed by inserting its greased stopper into $L$. In this way air is enclosed under a slight pressure in $A$, which prevents the cellophan membrane from sagging when $B$ is filled with

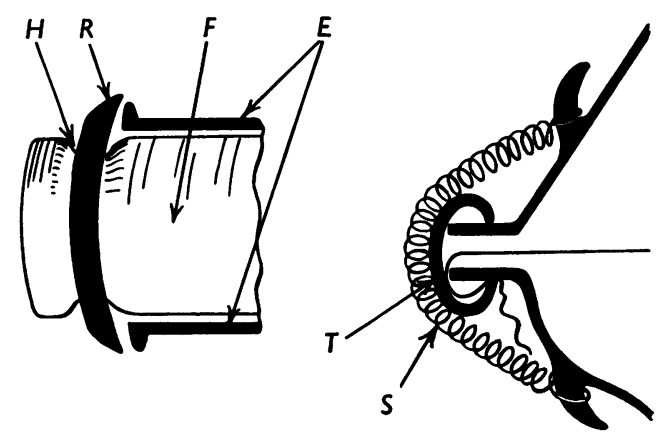

Fig. 2. Details of assembled vessel. $R$, rubber ring for securing key $F$ in barrel $E$; $S$, metal spring fastening upper and lower parts against each other; $T$, rubber tubing protecting the flanges.

liquid and obviates any correction for the calibrated volumes of parts $A$ and $B$ (see later under 'Calibration'). The glass rod $J$ is then introduced through the open $\operatorname{tap} E$ into $B$, where it rests on the membrane. $B$ is next completely filled with the required buffer solution by means of a pipette or burette, i.e. up to the junction of $B$ with the barrel $E$. A small amount of liquid (about $0.4 \mathrm{ml}$.) is withdrawn again by means of a calibrated pipette and the greased and slightly warmed key $F$ immediately inserted in such a way that the cavity $G$ communicates with the outside through e. By withdrawing some liquid from $B$ a corresponding air bubble is enclosed, which rises up to the cellophan membrane when the vessel is reversed into its proper position. Movement of this bubble mixes the liquid in $B$ during the experiment, and is essential for maintaining a steady rate of dialysis. The actual size of the air bubble is not critical. The cavity $\mathrm{G}$ is next filled with $\mathrm{H}_{2} \mathrm{O}_{2}$ solution of the required strength, by pipetting an amount of $\mathrm{H}_{2} \mathrm{O}_{2}$ slightly in excess of $G$ into $e$, and the key $F$ turned through $90^{\circ}$, whereby $G$ is separated from both the outside and the lower part of the vessel. The vessel is then again reversed (whereby the enclosed air bubble rises up to the membrane while the glass rod $J$ slides down into the position shown in Fig. 1) and held in the upright position by securing the outlet $e$ in a suitably perforated rubber bung. Lastly $1.0 \mathrm{ml}$. enzyme solution (dilute catalase) is pipetted on top of the membrane into $A$. The vessel is then ready to be connected to the manometer. Four vessels can be assembled for one experiment. In the present study differential manometers have been used, the compensating vessels being ordinary vessels of about the size of part $A$ or smaller. If the experiment requires a special gas or gas mixture this is introduced as in any ordinary manometer. In that case, however, the liquid to be filled into $B$ has to be equilibrated with the gas in question before it is pipetted into $B$. It is also possible to replace the air bubble, which is included in $B$, by a bubble of the required gas. This is done by passing a strong stream of the gas through the open barrel $E$ at the same time as inserting the key $F$.

Calibration. The different components of the vessel $(A, B$ and $G)$ are separately calibrated with mercury. For this purpose the cellophan membrane is replaced by a rigid partition. The upper part $A$ is calibrated according to the method of Dickens (1951). The volume of $G$, on which the initial concentration of the substance to be dialysed depends, has to be determined with the utmost accuracy. The vessel constants are calculated in the normal way, whereby the volume of fluid $\left(V_{F}\right)$ for the determination of the gas-solubility $(\alpha)$ is that contained in both the upper and lower parts of the vessel.

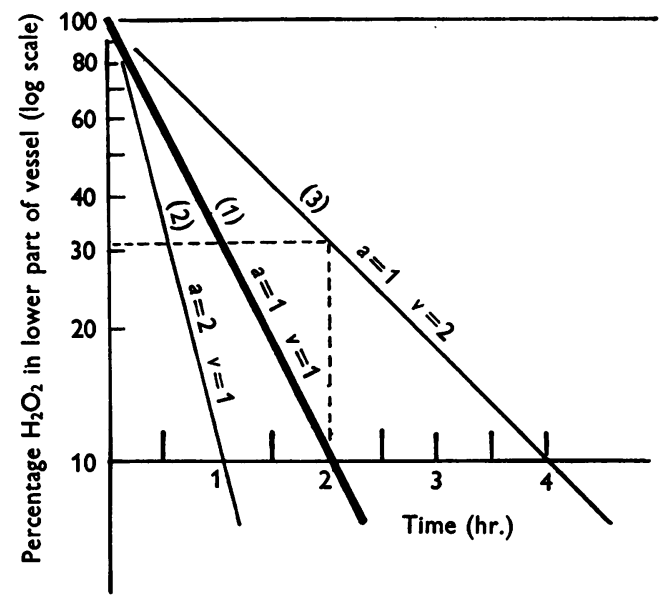

Fig. 3. Percentage decrease of $\mathrm{H}_{2} \mathrm{O}_{2}$ concentration with time in the lower part of vessels which differ in membrane area and volume: (1) control vessel with membrane area $(a)$ and volume of lower part $(v)=1 ;(2)$ vessel with membrane area $a=2$ and volume of lower part $v=1$; (3) vessel with membrane area $a=1$ and volume of lower part $v=2$. For explanation see text.

Allowance for variations. These allowances for the area of membranes and volume of the lower parts in a series of different vessels, on which the rate of dialysis depends, are made by relating the experimental results of a series of vessels to a control vessel used in that particular series, of which the membrane area $(a)$ and volume of the lower parts (Fig. 1, $B+G=v$ ) are each taken to equal 1 (Fig. 3, curve 1). On plotting the percentage decrease of $\mathrm{H}_{2} \mathrm{O}_{2}$ in the lower part of the control vessel (as calculated from the experimental data) the percentage decrease in any other vessel at a given time can be read off the graph. If, for example, all but $10 \%$ of $\mathrm{H}_{2} \mathrm{O}_{2}$ has dialysed through the membrane in the control vessel at $t=2 \mathrm{hr}$. (curve 1), then the same percentage is reached in half that time in a vessel which has 
the same volume below the membrane but twice the membrane area (curve 2). Conversely, $31 \%$ of the initial $\mathrm{H}_{2} \mathrm{O}_{2}$ remains at $t=2 \mathrm{hr}$. in the lower part of a vessel which has the same membrane area but twice the volume of the control vessel (curve 3). It is therefore possible to correct the experimental results for variations in membrane area and volume of the part below the membrane and thereby to evaluate the true effect of changes in the experimental conditions. In the present experiment membrane areas and volumes of the lower parts of different vessels agreed so closely that the correction necessary at any time was $<5 \%$.

Catalase. The enzyme used in these experiments was a highly purified preparation obtained from horse liver (Keilin \& Hartree, 1945a), the concentration of which is given in terms of its haematin content.

Hydrogen peroxide. A concentrated('100 vol.') solution was freshly diluted for each experiment in $0 \cdot 1 \mathrm{~m}$ phosphate buffer $\mathrm{pH} \mathrm{6.0} \mathrm{(12.5} \mathrm{ml.} \mathrm{Na}_{2} \mathrm{HPO}_{4}+87.5 \mathrm{ml}$. $\left.\mathrm{KH}_{2} \mathrm{PO}_{4}\right)$ to contain $50,100,200$ or $400 \mu \mathrm{l} . \mathrm{O}_{2} / 0.5 \mathrm{ml}$, which was the mean capacity of the tap cavity (Fig. $1, G$ ). This gave rising concentrations of $\mathrm{H}_{2} \mathrm{O}_{2}$ in the lower part of the vessel from 0.25 to $2.0 \mathrm{~mm}$. The concentration of the stock solution of $\mathrm{H}_{2} \mathrm{O}_{2}$ was checked at frequent intervals in separate manometric determinations, by tipping catalase into suitably diluted portions.

Ethanol. This was freed from aldehyde by refluxing over zinc $+\mathrm{KOH}$. The temperature of the bath was $20^{\circ}$.

\section{RESULTS}

In Fig. 4 the rate of decomposition of increasing amounts of $\mathrm{H}_{2} \mathrm{O}_{2}$ is plotted against time. As catalase is present in high concentration, the peroxide which dialyses is instantaneously decomposed. The rate of decomposition, therefore, equals that of diffusion. The following facts emerge: (1) Diffusion, as expected, follows an exponential course whereby at each concentration approximately $80 \%$ of the initial $\mathrm{H}_{2} \mathrm{O}_{2}$ diffuses within $2 \mathrm{hr}$. (2) The rate of diffusion of $\mathrm{H}_{2} \mathrm{O}_{2}$ is proportional to the initial concentration at the source. (3) The amount of decomposed (diffused) $\mathrm{H}_{2} \mathrm{O}_{2}$ which is manometrically determined at any time allows the remaining concentration at the source, i.e. in $B$, to be calculated. This is represented in the upper part of Fig. 4, which shows in logarithmic scale the percentage decrease of $\mathrm{H}_{2} \mathrm{O}_{2}$ concentration with time at the source. This was within the experimental error equal for all four concentrations of $\mathrm{H}_{2} \mathrm{O}_{2}$.

The experimental conditions allow quantitative analysis of the factors affecting the peroxidatic function of catalase, for the oxygen liberated in presence of ethanol under given experimental conditions is a direct measure of the efficiency of peroxidatic oxidation, thus:

Peroxidatic efficiency $(\%)=100 \times$ (oxygen liberated in control-oxygen liberated in presence of ethanol)/(oxygen liberated in control).
The following concentrations have been used in examining the interrelationships of catalase, $\mathrm{H}_{2} \mathrm{O}_{2}$ and ethanol: catalase, $2 \times 10^{-9}-2 \times 10^{-5} \mathrm{M}$; initial $\mathrm{H}_{2} \mathrm{O}_{2}$ at the source, i.e. in the lower chamber (Fig. 1, $B+G$ ), 0.25-2.0 mM; ethanol, 0.085$1.36 \mathrm{M}$.

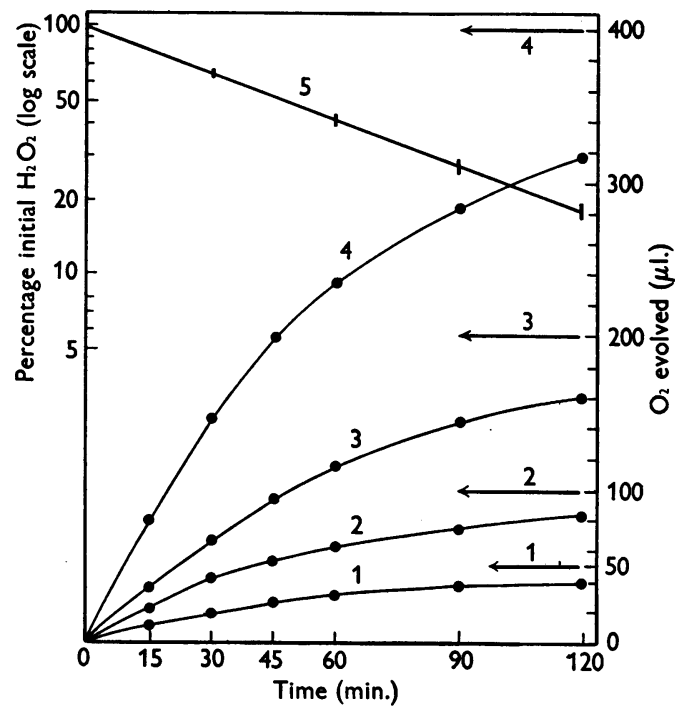

Fig. 4. Catalatic decomposition ( $\equiv$ diffusion) of increasing amounts of $\mathrm{H}_{2} \mathrm{O}_{2}$ plotted against time. Temp. $=20^{\circ}$;

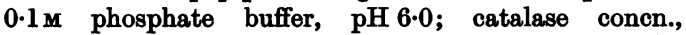
$2 \times 10^{-6} \mathrm{M}$. Initial $\mathrm{H}_{2} \mathrm{O}_{2}$ concentration in curves $1-4$ was $0.25,0.5,1.0$ and $2.0 \mathrm{mM}$, equivalent to $50,100,200$ and $400 \mu \mathrm{l}$. $\mathrm{O}_{2}$ per vessel. The arrows $1-4$ indicate the theoretical amount of initial $\mathrm{H}_{2} \mathrm{O}_{2}$ in each case. Curve 5 represents the percentage decrease of $\mathrm{H}_{2} \mathrm{O}_{2}$ with time in the lower parts of the four vessels plotted on a logarithmic scale.

In Fig. 5 the $\mathrm{O}_{2}$ developed from catalatic decomposition of diffused $\mathrm{H}_{2} \mathrm{O}_{2}$ in absence and in presence of ethanol is plotted against time. The curves differ because in presence of ethanol a large proportion of the diffused peroxide has not been catalatically decomposed but has been utilized for the peroxidatic oxidation of ethanol. In this, as in every other case, the formation of aldehyde, in addition to its characteristic smell, was qualitatively checked by a test with Schiff's reagent or by a brown coloration of a roll of $\mathrm{KOH}$-soaked filter paper (polymerization) which was occasionally included in the side bulb of the vessels. From curve 1 the amount of $\mathrm{H}_{2} \mathrm{O}_{2}$ remaining at the source and hence the percentage decrease with time of $\mathrm{H}_{2} \mathrm{O}_{2}$ below the dialysing membrane can be calculated. This is represented in the upper part of Fig. 5 (curve 1a). By similarly calculating the apparent decrease of $\mathrm{H}_{2} \mathrm{O}_{2}$ concentration at the source in 
presence of ethanol (curve $2 a$ ) a direct measure of the peroxidatic yield is obtained, which in this case is about $80 \%$ of the diffused $\mathrm{H}_{2} \mathrm{O}_{2}$.

The conditions of the experiment represented in Fig. 5 were obviously favouring the peroxidatic as opposed to catalatic function of catalase in so far as the concentrations of catalase $\left(2 \times 10^{-5} \mathrm{M}\right)$ and of ethanol $(0.34 \mathrm{M})$ were high while the peroxide concentration was comparatively low $(0.5 \mathrm{~mm})$.

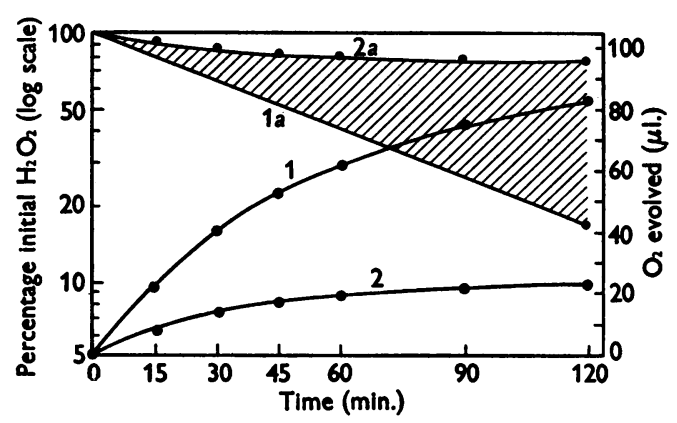

Fig. 5. Catalatic decomposition of dialysed $\mathrm{H}_{2} \mathrm{O}_{2}: 1$, in absence, 2 , in presence, of ethanol. Temp. $=20^{\circ} ; 0.1 \mathrm{M}$

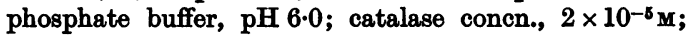
ethanol concn., $0.34 \mathrm{M} ; \mathrm{H}_{2} \mathrm{O}_{2}$ concn., $0.5 \mathrm{~mm}$ (100 $\mu$. $\mathrm{O}_{2}$ /vessel). $1 a$, Calculated percentage decrease of $\mathrm{H}_{8} \mathrm{O}_{2}$ concentration at the source (logarithmic scale); $2 a$, apparent percentage decrease of $\mathrm{H}_{2} \mathrm{O}_{2}$ concentration in presence of ethanol. The shaded area indicates the amount of $\mathrm{H}_{2} \mathrm{O}_{2}$ which has been utilized for the peroxidatic oxidation of ethanol to aldehyde.

It follows that in order to study the separate or mutual effect of variations in the concentrations of catalase, peroxide and ethanol on the peroxidatic efficiency suboptimum concentrations of at least one and sometimes two of the components of the system have to be applied. Thus in testing the effect of increasing concentrations of catalase (Fig. 6, curve 1) those of ethanol $(85 \mathrm{~mm})$ and of peroxide at the source (1 mM) have been kept low. The results show that peroxidatic oxidation increases with rising catalase concentration, reaching $70 \%$ with $2 \times 10^{-5} \mathrm{M}$ catalase. The rate of catalatic decomposition in absence of ethanol, however, was unaffected by varying the catalase concentration between $2 \times 10^{-5}$ and $2 \times 10^{-9} \mathrm{M}$.

Next the effect of rising concentrations of ethanol was tested (Fig. 6, curve 2) with a low catalase concentration $\left(2 \times 10^{-8} \mathrm{M}\right)$ and an increased supply of $\mathrm{H}_{2} \mathrm{O}_{2}(2 \mathrm{mM})$. Under these conditions the peroxidatic activity also increases with rising ethanol concentration.

Finally, the effect of increasing the supply of $\mathrm{H}_{2} \mathrm{O}_{2}$ was tested (Fig. 6, curve 3), catalase again being kept at a low concentration $\left(2 \times 10^{-8} \mathrm{M}\right)$, while the ethanol content was the same as in the experiment shown in curve 1 , namely $0.34 \mathrm{M}$. Here it is found that the peroxidatic efficiency decreases with increasing rates of $\mathrm{H}_{2} \mathrm{O}_{2}$ supply.

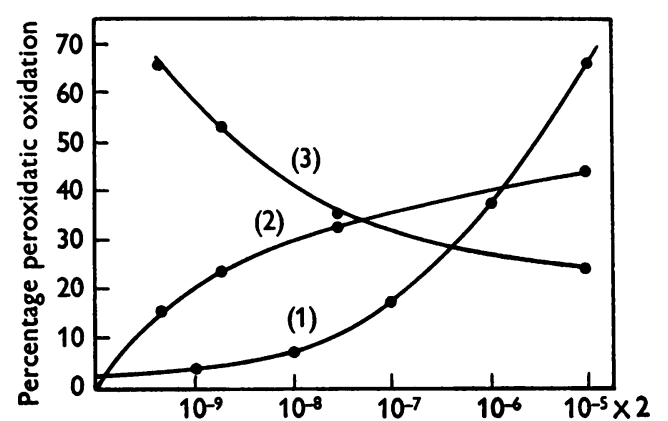

(1) Catalase concentration ( $M$ )

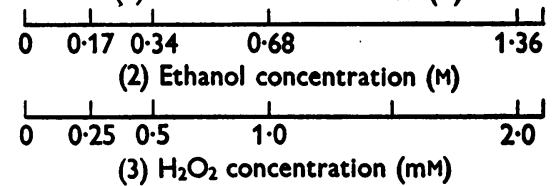

Fig. 6. Peroxidatic oxidation of ethanol by catalase as a function of the relative concentrations of catalase, ethanol and $\mathrm{H}_{2} \mathrm{O}_{2}$. Temp. $=20^{\circ} ; 0.1 \mathrm{M}$ phosphate buffer, pH 6.0; $2 \mathrm{hr}$. measurement. Curve 1: rising catalase concentration $\left(2 \times 10^{-0}-2 \times 10^{-5} \mathrm{M}\right)$, constant concentrations of ethanol (85 mM) and of $\mathrm{H}_{2} \mathrm{O}_{2}(0.5 \mathrm{~mm})$. Curve 2: rising ethanol concentration (0.17-1.36 M), constant concentrations of catalase $\left(2 \times 10^{-8} \mathrm{M}\right)$ and of $\mathrm{H}_{2} \mathrm{O}_{2}(2.0 \mathrm{mM})$. Curve 3: rising $\mathrm{H}_{2} \mathrm{O}_{2}$ concentration $(0.25-2.0 \mathrm{~mm})$, constant concentrations of catalase $\left(2 \times 10^{-8} \mathrm{M}\right)$ and of ethanol $(0 \cdot 34 \mathrm{M})$.

\section{DISCUSSION}

The method of intramanometric dialysis by which preformed $\mathrm{H}_{2} \mathrm{O}_{2}$ can be brought into contact with catalase at predetermined rates has made it possible, in the presence of ethanol, to obtain high yields of peroxidatic oxidation, that is, utilization of up to $80 \%$ of the available $\mathrm{H}_{2} \mathrm{O}_{2}$. Keilin \& Hartree $(1945 a)$, working with the system notatin-glucosecatalase-ethanol, have shown that, under their experimental conditions, the catalase concentration, in order to act peroxidatically, must be a thousand times higher than for catalatic decomposition of $\mathrm{H}_{2} \mathrm{O}_{2}$. This is corroborated by the experiment shown in Fig. 5. However, this implies no general rule but applies only to the specific conditions of a particular experiment. By suitably adjusting the concentrations of catalase, $\mathrm{H}_{2} \mathrm{O}_{2}$ and ethanol, it can be shown, as demonstrated in Fig. 6, that catalase at $2 \times 10^{-8} \mathrm{M}$, i.e. at $1 / 1000$ of the concentration necessary for approximately $80 \%$ peroxidatic efficiency in Fig. 5, is yet able to work 
with an efficiency of about $50 \%$, provided the concentration of ethanol is high relative to that of $\mathrm{H}_{2} \mathrm{O}_{2}$. For example, in the experiment shown in curve 2, Fig. 6, where the rate of diffusing $\mathrm{H}_{2} \mathrm{O}_{2}$ is great (initial concentration $2 \mathrm{~mm}$ ) very high concentrations of ethanol have to be used (up to $1.36 \mathrm{M}$ ) to obtain approximately the same peroxidatic efficiency as with a lesser supply of $\mathrm{H}_{2} \mathrm{O}_{2}$ $(0.25 \mathrm{~mm})$ at only one-quarter of the ethanol concentration (0.34 M, curve 3, Fig. 6). Even so, the ethanol concentration required under the experimental conditions used is about 10 times higher than that usually applied for coupled oxidation in enzymic systems. Chance (1849a-c, 1950a-c), who has demonstrated by means of his rapid-flow method that catalase forms successively two complexes with $\mathrm{H}_{2} \mathrm{O}_{2}$ and that the catalase- $\mathrm{H}_{2} \mathrm{O}_{2}$ complex I catalyses both the catalatic decomposition of further free $\mathrm{H}_{2} \mathrm{O}_{2}$ and the oxidation of ethanol by $\mathrm{H}_{2} \mathrm{O}_{2}$, assumes the velocity constant for the reaction of complex I with $\mathrm{H}_{2} \mathrm{O}_{2}$ to be 30000 times greater than for its reaction with ethanol (Chance, 1950c).

The method of intramanometric dialysis here described is not restricted to the subject under consideration. It could be used, for example, for removal of an inhibitory metabolite during the course of a reaction, as e.g. $\mathrm{H}_{2} \mathrm{O}_{2}$, by dialysing it away from the reaction mixture (that is, in the reverse direction to that in these experiments) or for the introduction of a substrate in very small amounts, e.g. ATP, which would otherwise be inhibitory, or for the addition to a highly purified enzyme on one side of the membrane of a metabolite produced by a crude enzyme preparation on the other side of the membrane.

\section{SUMMARY}

1. The peroxidatic activity of catalase has been studied by means of intramanometric dialysis whereby $\mathrm{H}_{2} \mathrm{O}_{2}$ of known concentration is introduced at a predetermined rate into a buffer solution containing ethanol and catalase.

2. The dialysis vessel has been described and its theory worked out for the simple case of diffusion and catalatic decomposition of $\mathrm{H}_{2} \mathrm{O}_{2}$.

3. By varying the concentrations of catalase $\left(2 \times 10^{-9-2} \times 10^{-5} \mathrm{M}\right)$, of ethanol $(0.085-1.36 \mathrm{M})$ and of initial $\mathrm{H}_{2} \mathrm{O}_{2}$ in the lower chamber $(0.25-2.0 \mathrm{~mm})$, i.e. by varying the rate of supply of $\mathrm{H}_{2} \mathrm{O}_{2}$, it has been found that the efficiency of peroxidatic oxidation $(a)$ increases with rising catalase concentration at constant ethanol concentration, reaching $70-80 \%$ with $2 \times 10^{-5} \mathrm{M}$ catalase; (b) increases with rising ethanol concentration at constant catalase and $\mathrm{H}_{2} \mathrm{O}_{2}$ concentrations; (c) decreases with rising $\mathrm{H}_{2} \mathrm{O}_{2}$ concentration at constant catalase and ethanol concentrations.

The method of intramanometric dialysis is not restricted to the subject under investigation.

The manometer vessels were made by Messrs W. G. Flaig and Sons, Waterloo Road, London, N.W. 2.

\section{REFERENCES}

Anan, K. (1951). J.'Biochem., Tokyo, 88, 19.

Chance, B. (1948). Nature, Lond., 161, 914.

Chance, B. (1949a). J. biol. Chem. 179, 1299.

Chance, B. $(1949$ b). J. biol: Chem. 179, 1311.

Chance, B. (1949c). J. biol. Chem. 180, 947.

Chance, B. (1950a). J. biol. Chem. 182, 643.

Chance, B. (1950b). J. biol. Chem. 182, 649.

Chance, B. (1950c). Biochem. J. 46, 387.

Dickens, F. (1951). Biochem. J. 48, 385.

Dixon, M. \& Keilin, D. (1933). Biochem. J. 27, 86.

Heppel, L. A. \& Porterfield, V. T. (1949). J. biol. Chem. 178, 549.

Keilin, D. \& Hartree, E. F. (1936). Proc. Roy. Soc. B, 119, 141.

Keilin, D. \& Hartree, E. F. (1945a). Biochem. J. 39, 148.

Keilin, D. \& Hartree, E. F. (1945b). Biochem. J. 39, 293.

Laser, H. (1954a). Biochem. J. 56, Xx.

Laser, H. (1954b). Biochem. J. 56, xx. 